\title{
Theoretical approaches to the organizational culture and the organizational climate: Exploratory research examples and best policies in health care services
}

\section{Eugenia Bitsani}

Human Recources management with emphasis in cultural, social services Technological Educational Institute of Peloponnese, Kalamata, Greece

\author{
Email address: \\ ebitsani@gmail.com
}

\section{To cite this article:}

Eugenia Bitsani. Theoretical Approaches to the Organizational Culture and the Organizational Climate: Exploratory Research Examples and Best Policies in Health Care Services. Journal of Human Resource Management. Vol. 1, No. 4, 2013, pp. 48-58.

doi: 10.11648/j.jhrm.20130104.11

\begin{abstract}
Organizational climate and organizational culture are two very interesting concepts for the aim of definition of a system of quality and continuous improvement within a healthcare organization. Ergonomically, the study of organizational climate responds to the need to assess the impact of organizational actions on daily work processes and is also a way to measure the health of an organization. Purely technical disputes on the problem of definition of organizational climate are related to the absence of an adequate theoretical model. We will examine them in a critical and analytical way. A further contribution examined is called "cultural". This theoretical model is based on an interactive approach and considers the interactions between the members of the group as a key determinant of organizational climate. The model further adds that a predominant influence on these interactions is exercised by the portion of meanings and knowledge that is mediated by organizational culture. We argue that the two concepts, climate and culture, are distinct constructs, but locked or linked.
\end{abstract}

Keywords: Organizational Climate, Organizational Culture, Organizational Behaviour, the Quality of Organization, Health Care Services

\section{Introduction}

In recent years, global community experiences an economic crisis of big depth, which, even if it was originally manifested in the USA -having been associated with bank debts and more specifically, the inability of paying the mortgage loans-, it soon became epidemic. Within this context, global economic news reports offers a specific definition of the concept of crisis, focusing on the bank and economic system of countries. Nevertheless, this term incorporates many other concepts, such as cultural crisis, value crisis etc. Initially, this term meant the decision to solve a problem so that a country, a business, an organization etc could come out from a difficult situation. In this framework the organizational culture and organizational climate are becoming more important than ever before because organizations need to ensure that those individuals who add value to the bottom line will want to stay in the organization and will want to continue pouring their effort into their work to the benefit of the organization.
(Castro, Martins 2010)[1]

Numerous studies provide evidence that the organizational climate exists as a principal, empirically verifiable, element (Burell 1979, 1996; Quaglino 1987; Buckingham and Coffman 2000; Bosch et al., 2008) [2], [3],[4],[5].

However, a full explanation of the modalities of its formation or its emergence has not yet been developed. The central problem concerning the formation of organizational climate is how individuals, who are subject to a wide range of stimuli, have a relatively homogeneous perceptions of themselves and, moreover, give them salient meanings to organizational life (Schneider and Reichers 1983)[6]. This paper explains that the two constructs, although conceptually distinct, are bound by the influence which organizational culture exerts on the formation of organizational climate. The importance of the research unit on culture and climate derives from the awareness that these are perhaps the two most valuable and powerful constructs that researchers have to include both expressive dimensions, communicative and human organizations, that 
the importance which they assumed in the structuring of organizational life (Ott 1989; Daft 2000)[7],[8]. The potential confusion between these two constructs is underestimated by most of the most recent research (Hofstede, Neuijen, Ohayr, and Sanders 1990) [9]. In a large scale empirical research which analyzed ten different organizations, researchers found that, as opposed to theoretical assumptions (Ekval 1987; Ozbilgin, Tatli 2008)[10],[11], the most distinctive characteristics items of organizational culture, mainly resided in the way in which organizational habits were perceived by members belonging to the organization. We are going to explain later that, this is the level at which we can appropriately define organizational climate. This new research shows an overlap between the two constructs, but also that there is a pressing need to theoretically explain relationships and intersections between organizational culture and climate.

\section{Climate and Culture}

\subsection{Organizational Culture: Theoretical Definition and Conceptual Approach}

Some observers allege that culture and climate are regarded as synonyms in the organizational theory. However, they are not the same and you would need to clarify the differences to understand both the constructs in order to carry out an adequate empirical exploration. Without these distinctions, climate can remain closed in the vastness of the concept of culture (as often occurred in the recent literature on the subject) and the two concepts suffer from this lack of clarity. Two issues are responsible for this confusion. The first is the absence of an appropriate definition of the concepts by researchers. The second is not recognizing that organizational culture and climate are concepts that have been addressed from different academic disciplines (which we will discuss below). So while the constructs are definitely linked, it is necessary to identify the small differences that exist between them.

Organizational culture has been variously defined (Hofstede 1980a, Schein 1990) [12],[13]. It denotes a wide range of social phenomena, including an organization's customary dress, language, behavior, beliefs, values, assumptions, symbols of status and authority, myths, ceremonies and rituals, and modes of deference and subversion; all of which help to define an organization's character and norms (Scott Mannion Davies and Marshall 2003, p. 925)[14].

Culture, in the sense that it is used here, can be understood as an idealized system (Schein 1999)[15] because a system focuses on types of meanings represented by values, formal rules, knowledge, beliefs and expressive forms (Pettigrew 1990; Parker 1992; Patrick 2010).[16],[17],[18] The conceptual aspect of culture contains several schools of thought, which are useful for understanding the role of culture in a context. The first is the cognitive school. This perceives culture as a system of knowledge or as templates learned through perceptions, beliefs, and evaluations that allow individuals to act in a manner acceptable to other members of the group or with other members of other groups (Bitsani 2006,p.35-37)[19]. This perspective encloses the positions presented first by Schneider and Reichers (1983; Hodgetts and Luthans 2003)[6],[20] in the interactive approach to climate. They both emphasize the implications for cognitive processes between groups' interactions and the relationships between these processes with the construction of individual meaning. There is also a parallelism between these positions, evident even in social psychology and anthropology, with tradition phenomenological sociology (Hofstede 1980b; Hofstede 1994) [21],[22].

The cultural perspective abandons what structural approach proposed about climate, which was seen as linked to formal property, and also those beliefs that were inherent in the perceptive and interactive approach, i.e. the individual examination of the psychological processes (Chan, Shaffer, Snape 2004)[23]. It emphasizes the social provisions, where the cultural features become very important. What is relevant is not inherent in the cultural significance, but in the way in which they guide the social conduct in its manifestations visible in organizational climate. In other words, the cultural approach by its analysis explores the dynamics through which (it delete) is produced a shared consciousness concerning the conditions in which these dynamics occur and how to successfully become significant. In brief, organizational climate is created by a collection of individual interactions modeling a common abstract part of attributes, as the culture of the Organization, by situational factors as contingencies that is the requirements imposed by organizational conditions (Schein1990)[13]. This approach moves the focus from individual perceptions as the main sources of climate, emphasizing instead the interaction between the members of the Organization (the point of view which is shared by the interactive approach).

Culture may be defined as a system of common values which can be estimated that people describe the similar organization culture even with different background at different levels within the organization (Robbin, Sanghi 2007)[24]. As Stewart (2010), stated that organization's norms and values have a strong affect on all those who are attached with the organization. He argues that it is considered by him that norms are invisible but if the organizations want to improve the performance of the employees and profitability, norms are the places first to look. ( Shahzad et al.,2012, p.977;)[25].

The cultural approach then stresses the critical role that culture plays in shaping the organizational processes that produce the organizational climate. It remains to explain and clarify, however, the relations between organizational climate and organizational culture. This will be discussed in the next section of this article.

"Speaking of organizational culture, some authors have designed the term culture as an all-inclusive concept that subsumes already different concepts and phenomena" (Trice, Beyer 1984a, p. 653; Gazi, Zyhpur 2009) [26] [27]. Trice 
and Beyer (1984b) [28] assume that one of the possible reasons for the lack of theoretical integration of organizational culture may be due to yper/inclusiveness of the concept of culture, the inability to identify specific areas in which put some fundamental concepts. They detect that culture is composed of two key elements: (1) the content, which consists of a network of meanings contained in ideologies, norms, values, beliefs, that unite people and allow them to interpret and understand the world out there; (2) the form or practices through which the meanings are expressed, or well established and communicated to members through myths, rituals and symbols,(Trice, Beyer 1993) [29] The two authors deny that researchers have distinct meanings that characterize a specific culture while explaining its various forms. A formal definition of organizational culture which takes into consideration the contents above comes from Schein: organizational culture is a set of basic assumptions that a certain group invented, discovered or developed when it managed to cover issues of adaptation to an external or internal integration, and which proved valid and, therefore, are captured and sent to new members as the proper way to feel, think and act on those problems (Argyris, 1993; Denison,1996 Cameron, Quinn 2011)[30],[31],[32]. The definitions of culture appeared in the literature emphasize the consensual expectations, assumptions and views that govern the social interactions (Trice, Beyer 1993) [29]. In this regard, they join the concept of tacit knowledge of Polanyi and regulatory support the concept of social action of Parson.

We understand that these definitions of culture do not refer to all models of behavior. The manifest behavior is determined by the cultural susceptibilities and situational contingencies arising from the external environment. So the behavioral variability may be due either to environmental contingencies or cultural contingencies. The model of cultural levels proposed by Schein (1985)[33] deals eminently with the nature "out of the awareness" of culture, so that we can see better the relationship(s delete) between the various cultures. It's a model particularly useful for linking, as in our resolutions, culture with climate. Culture is composed of various elements (special physical, behavioral rules, core values, etc.) that reflect a certain philosophy or social ideology underpinning those conceptual categories or hired to bring people to interpret and communicate things every day. The model distinguishes these elements addressing certain basic type "absences of culture" and addressing behaviors, and values that are observed in cultural events in "absence"(Schein 1996; Daft 2000)[34],[8]. In summary, culture is the basis of social relations. Culture is historically and socially constructed, incorporates deep structures of meaning, beliefs, assumptions and expectations which interact. It's an implicit aspect of social life that isn't readily observable and interpretable by a person outside the group. These deep structures represent the agreement on the reality for each group member.

The concept of organizational culture combines the concept of climate. Culture unlike climate has been extensively studied by researchers, in an attempt to systematize it in a unitary concept, to give a definition, to discuss what part of the concept of culture is part of climate (for example the norms, values, shared meanings and rituals, myths, artefacts, language e.tc). While the analysis of climate in organizations is to specify environmental influences on the motivation and behaviour, culture is a concept borrowed from anthropology and transferred in organizational studies along with all the know-how developed in decades of research on cultures of company lands and subcultures in Metropolitan communities (Hofstede 1980b, 1991; Patrick 2010b)[21],[35],[18]. A fundamental difference between climate and culture resides in the perspectives of disciplines that studied them. On the one hand, psychology research focused on climate studies, while anthropology on the study of culture. The first researchers interested in climate were all influenced by the school of thought of Lewin, focused on action research, research that is characterised by a multidisciplinary description of organizational dynamics for change and improvement of the organization. (Parker and Bradley 2000) [36].

\subsection{Organizational Climate: Theoretical Definition and Conceptuel Approach}

Organizational climate, in its structural dimension, is closely related with those inherent objective characteristics understood as physical environmental-structural characteristics and the working roles. The second level of analysis reflects the interpersonal dimension of work, including patterns of interaction between the members of a group in a given context and the dynamics through which individuals are integrated into the organizational culture, e.g. if cooperative or conflictual mechanisms are established. The third level, considered a core point in the analysis of climate, is the individual dimension, the individual perception of external conditions, the interpretation of the psychological processes that mediate context and personal requirements. In fact organizational climate will combine these three dimensions in a manner inseparable from each other.

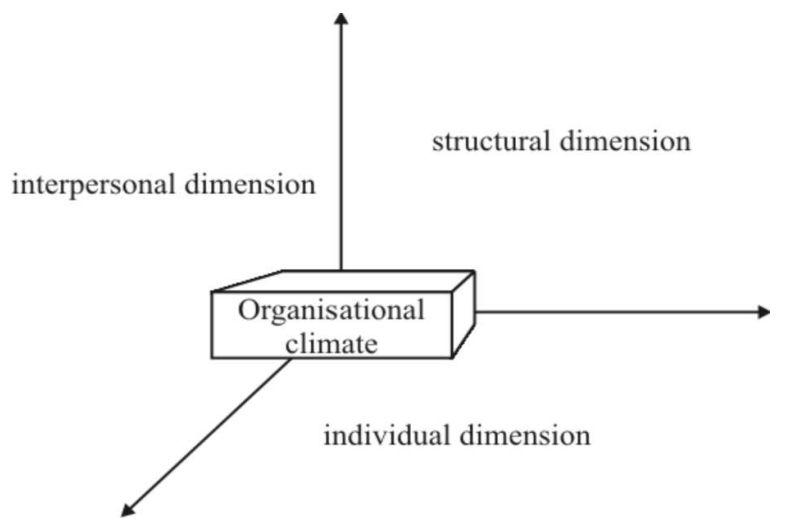

Figure 1. The dimensions of organizational climate. 
The first explanation on the formation of climate comes from structural approach (all approaches that we discuss in this article are briefly presented in figure I). This approach considers climate as a characteristic or attribute that belongs to the organization. These attributes exist independently of individual perceptions, as held by the organization itself. Guion proposed a change in empirical research regarding this issue by saying that if organizational climate is considered an attribute of the Organization, but inferred from perceptual measures, then the accuracy of perceptions should be validated through objective, external measures (Gordon and Di Tomaso 1992; Bitsani 2006)[37],[19] and Rentsch (1990)[38] have a specific and detailed analysis of the structural perspective. According to their point of view, climate is formed by objective aspects of the organizational structure, which can be the same size that is the degree of centralization of decisions, the number of hierarchical levels, the type of technology used, and how formal roles and personnel policies shall prescribe behavior. Among other research Martin (1992)[39], Burell (1996)[2], Daft (2000)[8], Chan Shaffer and Snape (2004)[23], showed the relationship between structural factors such as those listed above and organizational climate.

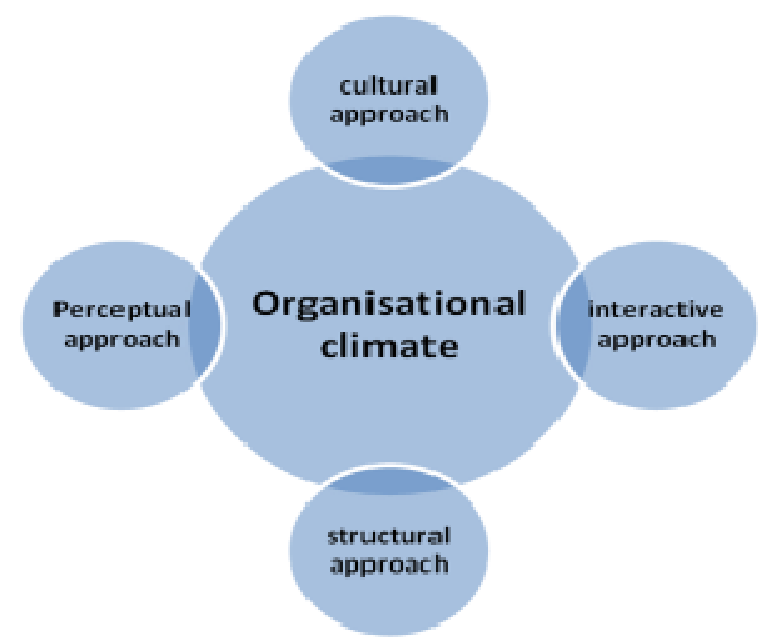

Figure 2. The approaches on the formation of organizational climate

As explained, we can see how the organizational structure produces an organizational climate independently from those individual properties received by members of the organization. In other words, climate is an objective demonstration of organizational structure that individuals experience and acquire. There are some dilemmas inherent in structural approach. First, since the structural factors of the type previously indicated commonly belong to entire organizations, structural approach cannot explain those searches that have tested different climates in workgroups belonging to the same organization (Gregory et al. 2008, Johnson 2003)[40],[41]. Second, since structural approach denies that climate arises in response to specific aspects of organizational structure, logical inference shows that organizational climate is in strict and significant relationship with structural features. Much research in the literature demonstrate a high degree of inconsistency between structure and climate and factors related to them (Bellandi De Simone, Zoppi 2005)[42]. An additional and perhaps more serious problem of structural approach is linked on the assumption that individuals are able to perceive the structural factors with remarkable (even if not complete) accuracy and that such perceptions describe the salient features of climate. In other words, this approach considers the inadequately subjective impact that structural variables have on individual reactions to a situation. This means that you have processes among individuals belonging to different groups that interact with each other and that format a common organizational culture.

Organizational climate is not essentially a set of perceptions (that are mediated by perceptive accuracy) of the characteristics of the organization, of which individuals take into account. If so, there should be no differences in measures of organizational climate and objective measures of organization, except for the error variance due to the inadequacy of the procedures of measure and/or the perceptual distortion. Although the structural approach suggests that the complete convergence between perceptual objective factors and organizational climate can be theoretically possible, similar conditions are unlikely because, as we will explain, organizational climate is not so much the measure of a collection of individual perceptions of organizational characteristics, as the measure of social significance attributed by the collective (Bosch, et.al., 2008)[5].

The proposed definition of climate indicates the possibility to build causal models designed to analysis, evaluation and forecasting of the effects, in terms of organizational performance and emerging problems arising from a set of causes that can be unveiled in the quality of the organizational climate. Climate is generally defined as the shared perception of "how things are around us". More precisely, climate is the shared perception of organizational policies, practices and procedures, both formal and informal. This level introduces the risk of excessive general information of the aspects which we investigate, while, as suggested by Schneider and Reichers,1983, Al-Lamki 2002, Cotton, 2004)[6],[43],[44], it is necessary to identify a focus to narrow the question of research on specific organizational policies, to discuss climate of substantive quality of living conditions within an organization (Mac Davitt, et.al.,2007, Shortell, et. al.,2001, Hartmann, et.al. 2009)[45],[46],[47] .

Researchers therefore propose a fundamental distinction between organizational culture and organizational climate. Culture is seen as something that resides within an organization, while climate relates to something that an organization meets in terms of an attribute or a quality (Cameron 1991, Daft 2000,. Shortell et al. 2000, Mallak et al. 2003, Scott et al 2003)[48],[8],[49],[50],[14]. This idea of culture promotes the study of culture as something "native". This approach is largely descriptive of the deep structure of organizations. 


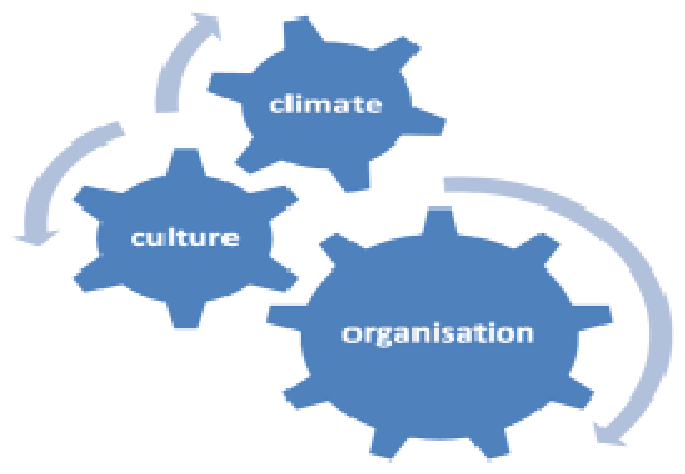

Figure 3. The first relation between culture and climate.

We switch to a construct of a more specific level that has its particular basis in the plans of an organization. In organizations there are many climates, and these were often identified into groups and subgroups of people who share common perceptions. For example, some studies have focused on climate for service and climate for security (Glendon 2001)[51]. Depending on the dissemination of a climate within an organization measurable by perceptions of members, we can consider the extent to which we can evaluate the impact of organizational actions in a longitudinal perspective (Castro, Martins 2010)[1]. It is exactly what we are proposing to do to implement a draft organizational ergonomics plan in healthcare services, with the aim of assessing the impact of the decisions of the management on the present climate and the prospect of a participatory management adapted to the needs of operators and recipients of the health service. Returning to relationships between climate and culture, culture has surely amplitude and a more pervasive character than climate, even if climate is more noticeable of culture for the members of an organization. Culture remains in the background of the daily interactions and practices, while climate has an influence most apparent on the behaviour of individuals (Zazzali et.al. 2007, Davidson 2000)[52],[53]. We can say that climate is considered a more superficial concept of culture as an index of quality of some important aspects of the current status of an organization, such as security, customer satisfaction or innovation. Culture is often seen as a temporal phenomenon, which can be part of an organization's strategies, while climate is more short-term and represents functional management tactics (Chiu Pan, Wei 2008)[54].

The parts of climate that have being typically assessed include autonomy, cohesion, confidence, pressure, support, recognition, loyalty and innovation. A classification of relationships between climate and culture, in addition to the aforementioned size of the amplitude and time, also includes the dimension of depth. In a three-tier model proposed by Glendon and Stanton (1999)[55] (Figure 4), in the relatively accessible surface aspects of an organizational culture, can be found observable behaviours and artefacts produced by an organization. At an intermediate level can be found the attitudes and perceptions, which are not directly observable, but that can be investigated with questionnaires or through structured observations. Finally on the deepest level there are the values and the basic assumptions, which are more untraceable.

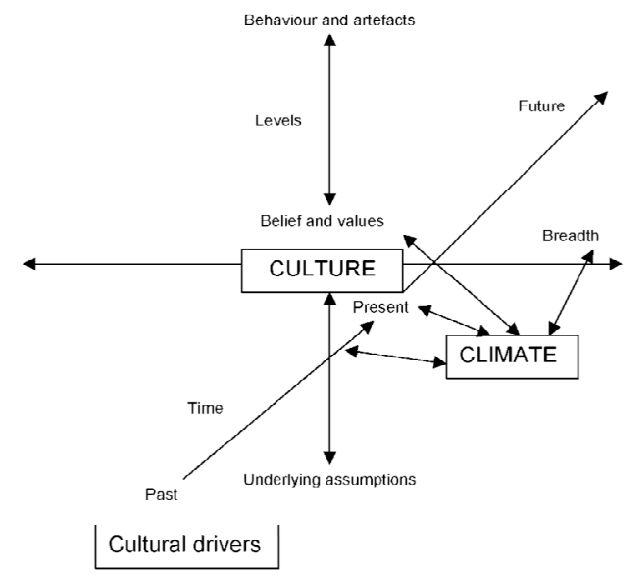

Figure 4. Organizational culture and organizational climate (Glendon and Stanton 1999).

As shown in Figure 4, these elements are in a sense the interaction between cultural levels. Figure 4 shows what constitutes interactive levels of culture (adaptation reproduced from Schein 1985, p. 4)[56]. Level 1 of the diagram shows the elements that are more visible, but which often are undecipherable without in-depth knowledge of the culture of the group. Level 2 shows values. These often are articulated explicitly and consciously provide the legislation in guiding the behavior of members in certain key situations. These values are reinforced in time, through cognitive transformations that change the state of beliefs on which they are based. In Level 3 are the assumptions underlying such a culture, where a former mere hypothesis or fundamental value become reality. This conception of the concept of culture clarifies how it could be considered an independent property and permanently defined a social unit. This occurs when you have stable interactions between entities where they acquire shared visions and when these shared visions operate for a period sufficiently long to become an awareness of what was out of the awareness of the subject.

\section{The Analysis of Organizational Climate and Culture in Healthcare Organizations}

Health system reforms have until recently tended to focus primarily on structural change. According to Scott the introduction of managed care in the United States, the establishment of standard-setting bodies such as the National Institute for Clinical Excellence (Department of Health 1998)[57] in the United Kingdom, the development of medical error reporting systems in Australia, are examples of this approach (Ferlie, and Shortell, 2001)[58]. However, recent studies show that structural changes alone 
do not deliver anticipated improvements in quality and performance in health care (Chiu et al 2008, Park, Kim, 2009; Shortell et al 2000; Speroff et al. 2010, )[54],[59],[50],[60]. As a result, we hear calls for "cultural transformation" to be wrought alongside structural change in order to deliver improvements in quality and performance. In the decade since the culture perspective burst on to the organizational studies scene, the perspective has waxed and waned in influence and vitality (Scott 2003, Gerowitz 1998, Hartman et. al. 2009, Mc Connel, 2005)[14],[61],[48],[62]. Emerging from the odd confluence of the formidable forces of postmodernism and Japanese competition, the culture perspective helped to introduce a decade of paradigm wars that have served to redefine the epistemological fault lines within the discipline (Burrell and Morgan 1979)[63]. These paradigm wars have sharpened our skills at epistemological repartee, but, ironically, culture research has still fallen short of both theoretical and practical expectations, even as it has become an established topic area within the field. Indeed, undeniable signs of "maturity" are increasingly apparent in the recent culture literature. Culture textbooks have been published (Ott 1989)[7], and an unusually large number of books have recently appeared (Denison 1990; Ingersoll et al, 2000; Martin 1992; Frost et al. 1992; Seago, 1997, Gregory et al., 2008)[64],[65],[39],[66],[67],[40].

In addition, several comparative studies have recently appeared in leading organizational journals, applying conventional quantitative research techniques to the study of culture (O'Reilly Chatman and Caldwell 1991, Hofstede Neuijen Ohayv and Sanders 1990, Gordon and Di Tomaso 1992)[68],[9],[37]. These studies have appeared, even though other authors have argued that the application of conventional quantitative techniques to culture research runs the risk of reducing culture to "just another variable in existing models of... organizational performance" (Rad 2006)[69]. More perplexing, however, is the fact that many of these most recent quantitative culture studies have become virtually indistinguishable from an older, and now neglected research area of organizational climate. Why is it, for example, that when O'Reilly, Chatman and Caldwell (1991)[68] ask questions about risk-taking as an organizational trait, the field of organizational studies labels it as "organizational culture" yet when Litwin and Stringer (1968)[70] Knippenberg, de Dreu, Homan , (2004)[71] asked similar questions about risk-taking, that the field labeled it as "organizational climate?" Does this similarity have implications for the recent history and future trajectory of research on organizational culture? (Scott Mannion Davies and Marshall 2003)[14].

Research method for the organizational culture and the analysis of organizational climate in healthcare services requires the use of a questionnaire of psychosocial type, to be administered to a representative sample of employees, in order to investigate the perception of climate based on opinions and beliefs of those selected in relation to their working conditions. We can anticipate that we will get particularly important comments tracked by in-depth interviews with some representatives of those constituting the corporate organization (Shortell et al 2000)[50]. This second round of interviews would aim to use the specific contents of the issues being studied and highlight additional data that affect organizational climate. In addition to the quantitative survey, the observation of the context of the survey, although occasional and unstructured could provide important information on the reliability of the self reported data of a questionnaire. Qualitative integration of observation data gives meaning and substance to the interpretation of quantitative data that need to be contextualised and provide useful guidance and requirements for management. More specifically, organizational climate is studied in an empirical manner through the assessment of the environmental attributes of those who live in that environment. A personal value has been defined as what a person tries to get... because it leads to their "well-being".

The latent staff value serves as an indicator to determine what a person believes is significant for his wellbeing in a lab environment, or for the quality of an organization. James and James argue that the assessment of the work environment depends directly on measures of psychological climate. According to these two authors psychological climate variables are grouped into four factors: (1) commitment to work and independence; (2) support of superiors; (3) role stress and lack of harmony; (4) cooperation in the group and amicability. The emphasis on psychological aspects reflects traditional psychological studies focusing on individual differences, on personal experiences and emotional assessments. The main hypothesis is that individuals go through different kinds of learning, own different skills and different self-regulatory systems; all of them factors that will affect directly the assessment of the working environment.

Undoubtedly, the subjective component of the study of organizational climate is critical, as people always respond emotionally to the environmental characteristics they receive. But it would not be correct and comprehensive, for the purposes of analysis, to reduce climate studies just as studies of subjective assessment. The criticism on the concept of climate highlights a fundamental question: Whether climate is a property of the individual, the organization, or both. While it remains a fact that the subjective assessment by a questionnaire is the essential tool for the analysis of climate, we must not overlook, in our opinion, the subject of evaluation, i.e. the subjectively observable organizational and structural set of attributes and features that constitute the basic material of the organization. This means that every structure, at the aggregate level, brings with it a certain amount of determinism that influences behaviours and individual beliefs.

Another study by Stordeur and colleagues (Stordeur and D'Hoore, 2007)[72] involved a large sample of nurses employed in 12 hospitals. Using a questionnaire, including perceptions of job demands, work schedules and 
organizational climate, researchers aimed to identify structural and managerial characteristics of low- and high-turnover hospitals. The researchers found that whereas selected indicators of hospital structure were comparable between attractive and conventional hospitals, profiles of nurse perceptions towards the organizational features and climate were significantly different. The authors concluded that attractive hospitals with selected organizational characteristics succeeded in nurse attraction and retention.

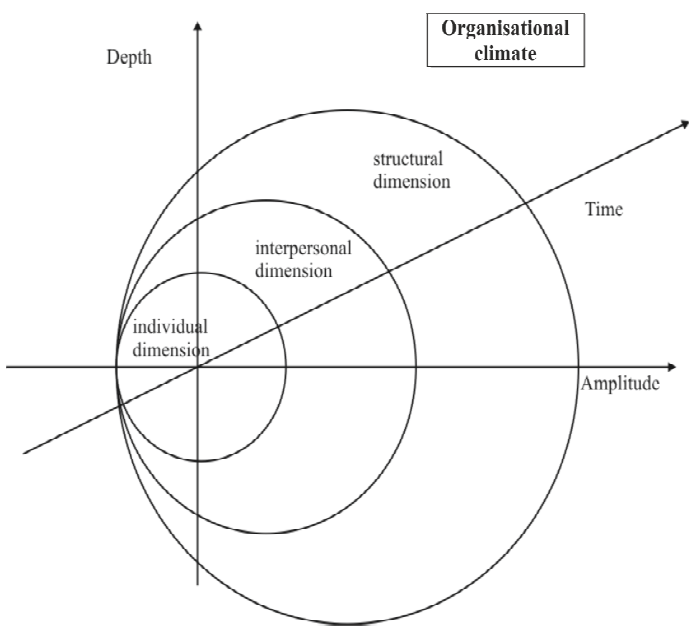

Figure 5. Organizational climate in the hospitals (Belladi De Simone and Zoppi Centro Ricerche in Ergonomia 2005)[43]

\section{The Relevance and the Role of Human Factor and Interpersonal Relations in the Organizational Climate Healthcare Services}

The relevance and the ruole of human factor and interpersonal relations in the organizational climate healthcare services

The diagnosis and treatment services that healthcare services provide are characterized by a high degree of participation. Diagnosis produces knowledge about the state of health of a patient while treatment produces changes on the sick body that in most cases are invisible and intangible but are effective to solve the problem. The degree of involvement of the client-receiver with the health service is very high, especially at the stage of diagnosis where the patient actively takes part in the process of the interpretation of his health history. The third section focuses on the fact that the use of a service takes place simultaneously with the production process, in contrast with a product, where production and delivery are separate in time. In other words, while a car is put on the market at a different time than the time it was produced, a ticket for a journey is used at the time of delivery of transport services. (Davies, et.al. 2000.)[73]

In a hospital context, a patient benefits from the service, at the very moment of his presence within the facility. This decisive point has implications for the effectiveness of the quality of service delivery: it is not easy to monitor compliance of a service with quality standards, provide a deadline, a cut point in time when we can say with confidence that the service delivery has finished and the next step is to conduct assessment. In the case of health service, quality might be high at the stage of admission of the patient and poor at the time of discharge from the hospital. If in this procedure described we add the subjectivity of evaluation, that is reflected in paragraphs 1 and 2, we need to analyze the process of reviewing and verifying quality in delivery of services (Hartman, et. al.2009)[47].

The recent research by Speroff T. and colleagues from the Department of Medicine, Center for Health Services Research, Veterans Affairs Tennessee Valley Healthcare System, Vanderbilt University School of Medicine, Nashville, Tennessee USA (Speroff , et. al.,2010)[61] involved a large sample of nurses and other staff employed in 40 Hospital Corporation of America hospitals. (1406 nurses, ancillary staff, allied staff and physicians). Using a questionnaire, including perceptions of Bureaucratic organizational culture and the quality improvement, whereas organizations with group (teamwork) culture are better aligned for quality improvement, and to determine if an organizational group culture shows better alignment with patient safety climate. The researchers found that among the 40 hospitals, $37.5 \%$ had a hierarchical dominant culture, $37.5 \%$ a dominant group culture and $25 \%$ a balanced culture. Group culture hospitals had significantly higher safety climate scores than hierarchical culture hospitals. The magnitude of these relationships was not affected after adjusting for provider job type and hospital characteristic. Thus their conclusion consists in this determination: "Hospitals vary in organisational culture, and the type of culture relates to the safety climate within the hospital. In combination with prior studies, these results suggest that a healthcare organisation's culture is a critical factor in the development of its patient safety climate and in the successful implementation of quality improvement initiatives" (Speroff, et. al, 2010)[60].

The concept of organizational climate that we propose is a global measure of the quality of the work process, particularly effectively organized to achieve the production of a service (Callen, Braithwaite, Westbrook 2007)[74]. Users of public health services, who enter facilities, actively experiencing diagnosis and treatment, perceive the quality of treatment received, in terms of attention and care as well as directives and treatments. Patients breathe the atmosphere of a hospital because they themselves are part of it at the time of need. In the delivery of a service, qualities of working conditions are directly visible to users. The complexity and delicacy of health services make patients more sensitive in cues from the staff: a shift in the mood of a professional can compromise the tranquility and confidence of a patient already in serious anxiety for his own health. Good psychological climates on the behalf of employees, interpersonal relations of good quality and, above all, structural conditions that promote the well-being of employees enable us to expect a service of good quality and 
to predict user/citizen satisfaction. Ergonomic analysis of climate is especially relevant to the assessment of the impact of outside intervention that introduces changes on climate (Aiken, Clarke and Sloane 2002)[75].

In this framework, a hospital's culture is reflected by what is valued, the dominant managerial and leadership styles, the language and symbols, the procedures and routines, and the definitions of success that make a hospital unique. In the health care organizations physicians and nurses are generally familiar with the concept of culture and its importance in the provision of individualized patient care.

A hospital's culture is reflected by what is valued, the dominant managerial and leadership styles, the language and symbols, the procedures and routines, and the definitions of success that make a hospital unique. In the health care organizations physicians and nurses are generally familiar with the concept of culture and its importance in the provision of individualized patient care. Therefore, organizational culture has been considered as a variable influencing hospital performance that contribute to quality of care (Clark 2002, Lindberg, Rosenqvist 2005)[76],[77], and a tool that can be used for better nursing (Rheem 1995)[78], medical (Ferlie and Shortell 2001)[51], patient, and system outcomes including improved workplace environments (Ozer et al 2008)[79] and patient and staff safety. Moreover, it has been suggested that regardless of individual's motivation, capabilities and resources, a supportive work culture may have significant impact on the feelings towards one quality of working life as well as on health consequences in this health sector (Aiken et al 2002, Callen et al 2007, Scott and Estabrooks, 2006)[75],[74],[80].

Another research from Italy by Giorgio Soro and colleagues from the Department of Psychology at Torino University and centers-communities of practices: the Oncological and Hematological Subalpin Centre (C.O.E.S), with prof. Ciuffreda, primary hospital; Pain Therapy and Palliative Care with prof. De Luca, primary hospital; Psych-oncology with prof. Torta, primary hospital e university teacher, to study the organization culture and the leadership in Italian Hospitals. The research group approved the value of climate and the feeling of confidence as the most important factor for the quality in the hospitals and the style of the leadership as well.

These centers are considered as communities of practices because there were practices oriented to the new model hospital worker with great attention to care, practices characterized from one dynamics personal-professional, practices based on integration between sanitary staff and caregivers. All of these are proved very useful also to plan and analyze the Hospital organization.

The study's approach to best practices is focused on 'personal-professional presence': the natural psychological expertise made by the competence "to be", the competence to be recognized like one person, the competence to move toward the others. Soro's research group approved, that it's possible to recognize best practices in the charitable network when the customers take part to the process of appraisal and design/plan of the existing and future services; or when health professionals use a collegial approach and the power is linked to the knowledge and not to the position. Also they suggest the Total Quality management as best practices in quality services, may be, in forms of accreditation to excellence or in risk management. Finally, if we consider health performance as help relation, the research of best practices drives toward a new conception of caregiver: not only needy of support but also one of the main informal charitable resource. (Barisone et al. 2007; Soro 2007; Soro 2008) [83][84][85].

Their approach comes from the search project: The image of the excellence. Leadership in Great Symphonic Orchestras (Acquadro Maran 2001) [86] in which 'presence' is the psychological natural expertise declinable like competence at 'being here' and to be recognized in our individuality but also like competence that orients us to the others (Soro, 2007) [84].

According Soro (2007) [84] there is a circle of confidence within orchestras and host conductor. The psychological process of confidence has four steps.

The holding process (receive, accept, contain, take care, adaptation) describes the confidence relation between group's member. Through the holding process, everyone experiences well-being. This produces the second step: personal involvement, engagement, care in interaction, in work, in intellectual adventures, and in general positive commitment to organizational results (Soro, 2012)[87].

A positive continuous involvement produces the third step, the sense of groupship: a positive orientation to understand and reproduce an attitude of sense making about the common membership context.

If everyone feels a positive sense of holding in the group and the process can reproduce itself, more and more, as a spiral, as a virtuous circle or, in negative, vicious circle.

In short the circle of confidence is a self and group efficacy expression, a positive Member Leadership Context for all, and this cicle of confidence is related with the hospital's culture and organization's culture directly. import your prepared text file. You are now ready to style your paper; use the scroll down window on the left of the MS Word Formatting toolbar.

\section{Conclusion}

This paper has argued that one of the most enduring differences between culture and climate stems from their respective theoretical foundations. Both are rooted in dominant theoretical traditions of their time, climate research growing out of Lewinian, field theory and culture research growing out of the social construction framework (Burell 1996)[2]. Even this boundary is not always so clear. The research of Chatman (1991)[81] and O'Reilly Chatman and Caldwell (1991)[68] reflects many aspects of the Lewinian framework, and Ashforth (1985)[82] or Schneider and Reichers (1983)[6] can easily be viewed as describing the social construction of organizational contexts (Scott 
Mannion Davies and Marshall 2003)[14].

What is important in this study is the use of cultural elements as rituals and symbols from which the researchers draw those aspects and practices that can typically be associated to the size of organizational climate. Moreover these practices elements distinguish between different organizational cultures, as proposed in this paper which stresses the need for a theoretical explanation linking climate and culture of an organization of health care sector. It also proposes a measure of empirical validation of the theoretical link between these constructs. According to our position the two concepts, climate and culture, are distinct constructs, but locked or linked. They are linked in two aspects. First, they overlap in the components of the expressive and communicative dimension of social organizations.

Climate performs those behavioral characteristics and attitudes of participants that are more accessible to external observers. While on the other hand, culture represents more implicit aspects of an organization (Bitsani 2006)[19]. It contains those collective fundamental values and meanings of the members of an organization which are manifest indirectly through metaphors and inner shared mindsets sensations that are not immediately interpretable from outside. The second aspect in which culture and climate are related is through the influence that the central values historically constructed and the meanings embedded in organizational culture have in determining the attitudes and practices that are included in the organizational climate. Culture is the source of continuity and action where adaptive behaviors are performed in organizational climate from which they strengthen.

\section{References}

[1] Castro, M., \& Martins, N. (2010), "The relationship between organisational climate and employee satisfaction in a South African information and technology organization", $S A$ Journal of Industrial Psychology/SA TydskrifvirBedryfsielkunde, 36(1), A., 1-11.

[2] Burrell, G.(1996). "Normal Science, Paradigms, Metaphors, Discourses and Genealogies of Analysis." ,In Handbook of Organization Studies, (1996 ed.), eds S. Clegg, C. Hardy, and W. Nord, London: Sage, pp. 642-658.

[3] Quaglino, G. (1987), I climi organizzativi, Bologna: Il Mulino.

[4] Buckingham, M., and Coffman, C. (2000), First Break All the Rules. London: Simon and Schuster.

[5] Bosch, M., Dijkstra, R., Wensing, M., Van der Weijden, T., and Grol1, R. (2008), "Organizational culture, team climate and diabetes care in small office-based practices", $B M C$ Health Services Research 2008;8:180

[6] Schneider, B. and Reichers, A.E. (1983), "On the etiology of climates", Personnel Psychology, 36, 19-39

[7] Ott, J. (1989). The Organizational Culture Perspective. Chicago: Dorsey.
[8] Daft, R.L. (2000), Organization Theory and Design. Mason, $\mathrm{OH}$ : South Western College Publishing.

[9] Hofstede, G., Neuijen, B., Ohayr, D., and Sanders, G. (1990), "Measuring organizational cultures: A qualitative and quantitative study across twenty cases". Administrative Science Quarterly, 35(2), 286-316. 25

[10] Ekvall, G. (1987), "The climate metaphor in organizational theory". in B. Bass and P. Drenth (Eds.) Advances in Organizational Psychology. Beverly Hills, CA: Sage

[11] Ozbilgin M., Tatli A. (2008), Global diversity management: An evidence-based approach. London, England: Palgrave

[12] Hofstede, G. (1980a), Culture's consequences: International differences in work-related values. Beverly Hills:Sage.

[13] Schein, E. (1990), “Organizational Culture', American Psychologist 45, 109-119.

[14] Scott, J. T., R. Mannion, H. T. O. Davies, and Marshall M. I.(2003), "The Quantitative Measurement of Organizational Culture in Health Care: A Review of the Available Instruments" in Health Services Research 38,3, 923-945.

[15] Schein, E. (1999), The Corporate Culture Survival Guide, San Franscisco: Jossey-Bass.

[16] Pettigrew, A. (1990), "Organizational climate and culture: Two constructs in search of a role". In Schneider (ed.) Organizational climate and culture, San Francisco: Jossey-Bass, 413-433.

[17] Parker, M. (1992), "Post-moderns organizations or patmodern organization theory?" Organizational studies, $12(1), 1-17$.

[18] Patrick, H. A.(2010), “Organization culture and its impact on diversity openness in the information technology organizational context", Dimensions, 1(1), 67-72

[19] Bitsani E., (2006), Human Resources Management, Athens: Dionikos(in Greek) 27-35.

[20] Hodgetts and Luthans, F. (2003), International Management: Culture, Strategy, and Behavior. New York: McGraw-Hill/Irwin, Fifth Edition.

[21] Hofstede, G. (1980), "Motivation, leadership and organization: Do American leadership theories apply abroad?", Organizational Dynamics, 9, 42-63.

[22] Hofstede, G. (1994), Cultures and organisation: Intercultural cooperation and its importance for survival: software of the mind. London, England: HarperCollins.

[23] Chan, L.M., Shaffer, A., Snape, E. (2004), 'In search of sustained competitive advantage: the impact of organizational culture, competitive strategy and human resource management practices on firm performance'. International Journal of Human Resources, 15, 17-35.

[24] Robbins, S. P. and Sanghi, S. (2007). Organizational Behavior, NewDelhi: Pearson Education.

[25] Shahzad F., Rana A., Ayesha Rashid, Lalarukh S.(2012), "Impact of Organizational Culture on Organizational Performance: An Overview in the interdisciolinary", Journal of contemporary research in business January 2012 vol 3, no 9, 975-985. 
[26] Trice, H. M., Beyer, J. (1984a), "Studying organizational cultures through rites and ceremo- nials", Academy of Management Review, no 9, 653-669.

[27] Gazi, I., Zyphur, M. J. (2009), "Rituals in Organizations: A Review and Expansion of Current Theory". Group \& Organization Management February 2009 Volume 34, no 1, 114-139.

[28] Trice, H. M., Beyer, J. (1984b), "Studying organizational cultures through rites and ceremo- nials.", Academy of Management Review, no 9, 653-669.

[29] Trice, H. M., \& Beyer, J. (1993), The cultures of work organizations, Englewood Cliffs, NJ: Prentice Hall.

[30] Argyris, C. (1993), Knowledge for action: A guide to overcoming barriers to organizational change, San Francisco: Jossey-Bass.

[31] Denison, D.R. (1996), "What is the difference between organizational culture and organizational climate? A native's point of view on a decade of paradigm wars". Academy of Management Journal, 21(3), 619-654.

[32] Cameron, K.S., Quinn, R.E. (2011), Diagnosing and Changing Organizational Culture: Based on the Competing Values Framework, San Francisco: Jossey Bass.-John Willey\& sons.

[33] Schein, E. (1985), Organizational Culture and Leadership, San Francisco, Jossey Bass.

[34] Schein, E. (1996), 'Culture: the missing concept in organization studies', Administrative Science Quarterly, 41, 229-240.

[35] Hofstede, G. (1991), Culture and organizations: Software of the mind, New York: McGrawHill.

[36] Parker, R., Bradley, L.(2000), 'Organizational culture in the public sector: evidence from six organizations', The International Journal of Public Sector Management 13(2), 125-141.

[37] Gordon G., Di Tomaso, N.(1992), "Predicting corporate performance from organizational culture." Journal of management studies, 29 (6), 783-798.

[38] Rentsch, J., (1990), "Climate and culture: Interaction and qualitative differences in organizational meanings". Journal of applied Psychology, 75(6), 668-681.

[39] Martin J., (1992), Cultures in organizations: Three perspectives, New York: Oxford University Press.

[40] Gregory, B. T., Harris, S.G., Armenakis A.A., Shook ,C.L. (2008), "Organizational culture and effectiveness : A study of values, attitudes, and organizational outcomes", Journal Bus Res, 1-7.

[41] Johnson, D. W. (2003), Reaching out: Interpersonal effectiveness and self-actualization (pp. 360). Boston, MA: Allyn\& Bacon.

[42] Bellandi, T., De Simone, P., Zoppi, O.( 2005), L'Analisi del clima Organizzativo, Firenze : Centro Ricerche in Ergonomia, Aziend USL 10.

[43] Al-Lamki, S. M. (2002), "Orientation: The essential ingredient in cross-cultural management", International Journal of Management, 19, 568.
[44] Cotton, P. (2004), "Developing an optimal organisational climate", Towards Australia's Safest Workplaces, Australia.

[45] MacDavitt, K, Chou, S.S., Stone, PW. (2007), "Organizational climate and Health Care Outcomes. The Joint Commission", Journal on Quality and Patient Safety 2007; 33(11),45-56.

[46] Shortell, S. M., Zazzali, J. L., Burns, L. R., Alexander, J. A., Gillies, R. R., Budetti, P. P., Waters, T. M., \& Zuckerman, H. S. (2001), "Implementing evidence-based medicine: the role of market pressures, compensation incentives, and culture in physician organizations", Med Care , 39(7), 162-178.

[47] Hartmann, C.W., Meterko, M., Rosen, A. (2009), "Relationship of hospital organizational culture to patient safety climate" in the veterans health administration. Med Care Res Rev (2009) 66, 320-338.

[48] Cameron K., Freeman S. (1991), "Culture congruence, strength and type". Res Org, Dev 5, 23-58.

[49] Shortell, S.M., Jones, R.H., Rademaker, A.W., Gillies, R.R., Dranove, D.,S., Hughes, E.F., Budetti ,P.P., Reynolds, K.S., Huang, C.F. (2000),"Assessing the Impact of Total Quality Management and Organizational Culture on Multiple Outcomes of Care for Coronary Artery Bypass Graft Surgery Patients.", Medical Care. 2000, 38, (2), 207-217.

[50] Mallak, L.A., Lyth, D.M., Olson, S.D., Ulshafer, S.M., Sardone, F.J. (2003), "Culture, the built environment and healthcare organizational performance", Managing Service Quality, 13,(1), 27-38.

[51] Glendon, A. I. (2001), "Safety Culture, in Karwowski” (ed.) International Encyclopedia of Ergonomics and Human Factors, London: Taylor and Francis.

[52] Zazzali J.L., Alexander J.A., Shortell, S. M. and Burns, L.R. (2007), "Organizational Culture and Physician Satisfaction with Dimensions of Group Practice" HSR, 42:3.

[53] Davidson, M.C.G. (2000), Organisational climate and its influence on performance.Unpublished doctoral dissertation, Brisbane, Queensland: Griffith University.

[54] Chiu, C.H., Pan, W.H., Wie, C.J. (2008), "Does organizational culture impact patient safety management?", Asian Journal of Health and Information Sciences, 3: 88-100.

[55] Clark, G. (2002), "Organizational culture and safety: an interdependent relationship". Aust Health Rev, 25(6), 181-9.

[56] Glendon,A.I., and Stanton N.A. (1999), "Safety culture in organizations" Safety Science 34, 193-214.

[57] Schein, E. (1985), Organizational Culture and Leadership, San Francisco: Jossey Bass.

[58] Department of Health. (1998), "A First Class Service, Quality in the NHS". London: Quality Management in Health Care $6,(3), 1-11$.

[59] Ferlie, E., \& Shortell, S.M. (2001), 'Improving the Quality of Health Care in the United Kingdom and the United States: A Framework for Change'. Milbank Quarterly, 79(2): 281-316.

[60] Park, J.S., Kim, T.H.(2009),“Do types of organizational culture matter in nurse job satisfaction and turnover intention"? Leadership in Health Services , 22, 20-38. 
[61] Speroff. T., Nwosu, S., Greevy, R., Weinger, M.B., Talbot, T.R., Wall, R.J., Deshpande, J.K., France, D.J., Ely, E.W., Burgess, H., Englebright, J., Williams, M.V., Dittus, R.S. (2010), "Organizational culture: variation across hospitals and connection to patient safety climate", Qual.Saf. Health Care. 2010 Dec., vol.19, (6), 592-596.

[62] Gerowitz, M. B.(1998). "Do TQM Interventions Change Management Culture?" Do TQM interventions change management culture? Findings and implications. Qual Manag Health Care 1998, 6,1-11.

[63] MC Connell, L C.R. (2005), "Larger, smaller, and flatter: the evolution of the modern health care organization". Health Care Management ,2005, 24,(2), 177-188.

[64] Burrell, G., a Morgan, G. (1979), Sociological Paradigms and Organizational Analysis, Gower, Aldershot.

[65] Denison, D. (1990), Corporate culture and organizational effectiveness. New York: John Wiley.

[66] Ingersoll, G L., Kirsch. J.C., Merk. S.E., Lightfoot, J. (2000), "Relationship of organizational culture and readiness for change to employee commitment to the organization". JONA , 2000,30, $11-20$.

[67] Frost, P., Moore, L., Louis, M., Lundberg, C., and Martin, J. (1992), Reframing organizational culture, Beverly Hills: Sage

[68] Seago, J. (1997), “Organizational Culture in Hospitals: Issues in Measurement." Journal of Nursing Measurement $5,(2), 166-74$

[69] O’ Reilly, C.A., Chatman, J. and Caldwell, D.F.(1991), "People and organizational culture: a profile comparison approach to assessing person-organization fit", Academy of Management Journal 1991,34, 487-516.

[70] Rad, Amm. (2006), "The impact of organizational culture on the successful implementation of total quality management". The TQM Magazine 2006, 18,(6), 606-625.

[71] Litwin,G.H., and Stringer, R.A., (1968), Motivation and organizational climate, Cambridge, MA: Harvard Business School Press.

[72] Knippenberg D. V., de Dreu C. K. W., Homan A. C. (2004), "Work group diversity and group performance: An integrative model and research agenda". Journal of Applied Psychology, 89, 1008-1022.

[73] Stordeur, S., D’ Hoore, W., NEXT-Study Group. (2007), " Organizational configuration of hospitals succeeding in attracting and retaining nurses" Journal of Advanced Nursing 2007, 57,(1), 45-58.

[74] Davies, H., Nutley, S., and R. Mannion, R. (2000), "Organizational Culture and Quality of Health Care." Quality in Health Care , 9, 111-119.
[75] Callen, JL., Braithwaite, J., Westbrook, JI. (2007), "Cultures in hospitals and their influence on attitudes to, and satisfaction with, the use of clinical information systems". Soc Sci Med (2007), 65,635-639.

[76] Aiken, L.H., Clarke, S.P., \& Sloane, D.M. (2002), "Hospital staffing, organization, and quality of care: Cross-national findings", Nursing Outlook, 50(5), 187-194.

[77] Clarke, S., Sloane, D., \& Aiken, L. (2002), "Effects of hospital staffing and organizational climate on needlestick injuries to nurses". Journal of Public Health, 92(7), 1115.

[78] Linbendberg, E., Rosenqvist, U.(2005), "Implementing TQM in the health care service: a four-year following-up of production, organisational climate and staff wellbeing". Int J Health Care Qual Ass 2005, 18, pp.370-384.

[79] Rheem, H. (1995), “The learning organization: Building learning capability", Briefing from the editors. Harvard Business Review, 73,(2), p. 10.

[80] Ozer, M., Bakir, B., Teke, A., Ucar. A., Bas, T., Atac, A. (2008), "Military Medical Graduates' Perception of Organizational culture in turkish military school". J Med Syst. ,32, 317-325.

[81] Scott, -Findlay S. and Estabrooks C.A.(2006), "Mapping the organizational culture research in nursing: a literature review", J.Ad. Nursening, 2006, 56, 498-513.

[82] Chatman, J. (1991), "Matching people and organizations:Selection arid socialization in public accounting firms" Admin. Science Quarterly,36,459-484.

[83] Ashforth, B. (1985), "Climate formation: Issues and extensions". Academy of Management Review, 10(4), 837-847.

[84] Barisone, M., Fringuellino, A., Soro ,G.(2007),“La presenza psicologica degli operatori sanitari nel percorso di cura dell'ictus cerebrale", Revista de Psicologia/International Journal of Developmental and Educational Psychology, 3,p p. $509-520$.

[85] Soro, G.(2007), "The Great Symphony Orchestra as a original antropology of the group", International Journal of Developmental and Educational Psychology, 3, 68-75.

[86] Soro, G. (2008), Relational Skills in Organizations, Spain: Cortina.

[87] Acquadro Maran, D. (2001), Leadership e imagine dell'eccellenza, Milano: FrancoAngeli.

[88] Soro, G.(2012), Democracy of the music, Torino: Selid. 